\title{
The Earth expansion theory and its transition from scientific hypothesis to pseudoscientific belief
}

\author{
P. Sudiro \\ Baker Hughes, SS 602, C.da Calcasacco - Villanova, 65012, Cepagatti, PE, Italy \\ Correspondence to: P. Sudiro (paolo.sudiro@bakerhughes.com)
}

Received: 13 January 2014 - Revised: 4 May 2014 - Accepted: 22 May 2014 - Published: 20 June 2014

\begin{abstract}
During the first half of 20th century, the dominant global tectonics model based on Earth contraction had increasing problems accommodating new geological evidence, with the result that alternative geodynamic theories were investigated. Due to the level of scientific knowledge and the limited amount of data available in many scientific disciplines at the time, not only was contractionism considered a valid scientific theory but the debate also included expansionism, mobilism on a fixed-dimension planet, or various combinations of these geodynamic hypotheses. Geologists and physicists generally accepted that planets could change their dimensions, although the change of volume was generally believed to happen because of a contraction, not an expansion. Constant generation of new matter in the universe was a possibility accepted by science, as it was the variation in the cosmological constants. Continental drift, instead, was a more heterodox theory, requiring a larger effort from the geoscientists to be accepted.

The new geological data collected in the following decades, an improved knowledge of the physical processes, the increased resolution and penetration of geophysical tools, and the sensitivity of measurements in physics decreased the uncertainty level in many fields of science. Theorists now had less freedom for speculation because their theories had to accommodate more data, and more limiting conditions to respect. This explains the rapid replacement of contracting Earth, expanding Earth, and continental drift theories by plate tectonics once the symmetrical oceanic magnetic striping was discovered, because none of the previous models could explain and incorporate the new oceanographic and geophysical data.

Expansionism could survive after the introduction of plate tectonics because its proponents have increasingly detached their theory from reality by systematically rejecting or overlooking any contrary evidence, and selectively picking only the data that support expansion. Moreover, the proponents continue to suggest imaginative physical mechanisms to explain expansion, claiming that scientific knowledge is partial, and the many inconsistencies of their theory are just minor problems in the face of the plain evidence of expansion. According to the expansionists, scientists should just wait for some revolutionary discovery in fundamental physics that will explain all the unsolved mysteries of Earth expansion.

The history of the expanding-Earth theory is an example of how falsified scientific hypotheses can survive their own failure, gradually shifting towards and beyond the limits of scientific investigation until they become merely pseudoscientific beliefs.
\end{abstract}




\section{Introduction}

At the beginning of 20th century, the contracting-Earth theory had been the dominant geodynamic model (Suess, 1904; Wilson, 1959; Billings, 1960) for more than 50 years (Dana, 1863), supported by authoritative scientists, and in line with the accepted ideas on the origin of the solar system (Kelvin, 1864). Planetary contraction was so deeply integrated in geologists' vision that mobilism appeared barely scientific (Simpson, 1943) and continental drift remained a marginal and largely controversial hypothesis for over 50 years (for a discussion on the subject, see Ruse, 1978; Hallam, 1983; Frankel, 1987; Oreskes, 1988).

Indeed, the experimental data available to geoscientists, especially those deriving from geophysical tools that could provide penetration and accuracy in the investigation of the planet, was very limited or non-existent; therefore any geodynamic hypothesis could only be largely speculative, although promising. Once new geophysical tools became available, integrated with an increasing amount of traditional geological information, the validity of Earth contraction started to be challenged. After the discovery of radioactivity, and that radioactive decay generated heat inside the planet, a slower cooling rate had to be assumed for our planet (Joly, 1909), implying that Earth was not contracting at all or the contraction was too small to generate the observed tectonic structures. Furthermore, the radiometric age determinations (Holmes, 1913; Badash, 1989) were essential in determining a reliable timeframe for the geological events that contributed to the undermining of the contraction theory (Stinner, 2002). Finally, paleomagnetic studies were showing that diverging apparent polar wandering paths on different continents confirmed the change of reciprocal continents' position through time (Runcorn, 1956; Carey, 1958; Collinson and Runcorn, 1960).

The problems faced by the contraction theory stimulated the investigation of alternative geodynamic models, including expanding Earth (Lindemann, 1927; Furon, 1935, 1941; Carey, 1958; Heezen, 1959; Wilson, 1960), pulsating Earth (Joly, 1908, 1925; Haarmann, 1930), and fixist-mobilist hybrids (Van Bemmelen, 1966). Although geologists were clearly open to new ideas, Ruse (1978), Hallam (1983), Frankel (1987) and Oreskes (1988) showed that the large majority of Earth scientists rejected mobilism and favored the fixist alternatives. It was only the discovery of the seafloor magnetic striping that finally led to the abandonment of fixist geodynamic models through the development of plate tectonics (Vine and Matthews, 1963; Wilson, 1963; Vine and Wilson, 1965; Vine, 1966; Dickson et al., 1968; Heirtzler et al., 1968). However, the new plate tectonics theory had only a superficial similarity with continental drift, because all previous mobilist and fixist geodynamic theories became obsolete after the revolutionary advances that occurred in geophysics occurred during the 1960s. Plate tectonics quickly became the fundamental framework for Earth sciences, con- sidered valid at least since 3-3.5 Ga (Condie and Kröner, 2008; Næraa et al., 2012). In its more than 50 years of existence plate tectonics has amply proved its ability to explain within a single context the most diverse geological phenomena, and it is supported by a great deal of evidence.

However, expansionism has not vanished at all in the Earth sciences community. Expansionist papers have been published in scientific journals, and sessions at the 30th International Geological Congress, Beijing (Dickins, 1996; Hongzhen et al., 1997), 32nd International Geological Congress, Florence (Anonymous, 2004), and 34th International Geological Congress, Brisbane (Anonymous, 2012; Choi and Storetvedt, 2012a, b) were dedicated to the expanding-Earth theory. Earth expansion has been the subject of specific symposia organized by major scientific institutions (Carey, 1983a; McKenna, 1983; Scalera et al., 2012). Finally, the Earth expansion theory has found some credit among biogeographers (Ager, 1966; Glasby, 1999; McCarthy, 2003, 2005a, b, 2007; McCarthy et al., 2007) because of some intriguing biogeographic transpacific correlations.

\section{The expanding-Earth theory before and after plate tectonics}

Like contractionism and continental drift,the expandingEarth theory also has a long history, dating back to the 19th century; however, it remained a marginal idea until the beginning of the 20th century, when some geologists suggested the possibility of Earth expansion (Carey, 1975; Scalera, 2003a, b). While continental drift gained little consensus because of the scientists' problem in accepting planet-wide migration of continents (see Ruse, 1978; Hallam, 1983; Frankel, 1987; Oreskes, 1988), the expanding-Earth theory had the merit of explaining with a fixist model the evidence of ancient continental connections, suggesting that continents fragmented and dispersed not because of lateral displacement but because of radial expansion while the planet was inflating (Heezen, 1959). Indeed, because of the very schematic knowledge about the structure of the planet available at the time, there are some interesting parallels between Earth expansion and Wegener's theory. Wegener (1929) did not consider crustal subduction or mantle convection; he connected India to both Africa and Asia in his Paleozoic paleogeographic maps, and believed that continental crust floored the Tethys Sea. Moreover, some expansionists accepted, like Wegener (1929), that the Pacific Ocean was older than the Atlantic and Indian oceans, because they believed the planet expanded following a linear trend. Therefore, the images of Earth in expansionist and mobilist views were not so radically different at the time. This also explains the existence of mobilist-expansionist hybrid hypotheses and some geologists' shifts of opinion from mobilism to expansionism and vice versa (Carey, 1975, 1988). 
The main argument for Earth expansion is the questionable claim that continental profiles have a perfect reciprocal fit on a smaller Earth, while mobilist reconstructions leave open gaps. To test this hypothesis, expansionists worked with tridimensional physical models of the planet, scaled at different sizes to verify the quality of the geometrical fit between continents on an increasingly small Earth (Carey, 1958, 1975; Creer, 1965; Barnett, 1969; Scalera, 2003b). The experimenters apparently failed to note that the process worked like a reversal of the contraction theory. Therefore, if the modern lithosphere had to adjust to a smaller Earth this would not just decrease intercontinental distances but also increase the deformation of the continents. What expansionists were also unable to provide was a valid mechanism increasing Earth's size, although the speculations of eminent astrophysicists and physicists provided some support to the possibility of planetary expansion. Hoyle (1948) proposed the steady-state cosmologic model, postulating the continuous creation of new matter in the universe, and Dirac $(1937,1938)$ published the large numbers hypothesis, which implied a change of the universal gravitational constant with time and the creation of new matter (Shneiderov, 1943; Jordan, 1966, 1973).

The discovery of the magnetic stripes on the bottom of the oceans was the crucial evidence that oceans were expanding, disproving the contraction theory, but expansionists could also present the initial, localized evidence of oceanic expansion as proof of planetary expansion. The persisting appeal of expansionist theories, or the difficulty to adopt mobilism, is confirmed by the several papers combining moderate expansion with limited drifting (Holmes, 1965; Hospers and Van Andel, 1967; Van Hilten, 1968; Owen, 1976; Steine, 1977) that were published during the transition years towards the widely accepted plate tectonics. However, improved and expanded geophysical data removed the reasons and uncertainties that initially motivated support for planetary expansion. Moreover, plate tectonics succeeded in integrating preexisting geodynamic hypotheses, like mantle convection (Holmes, 1929, 1931; Hess, 1962) and subduction (Wadati, 1935; Benioff, 1954, 1955; White et al., 1970; Schellart and Rawlinson, 2010), and support for Earth expansion rapidly vanished. Finally, the only supporters of expansion remained the radical expansionists that rejected any subduction (Carey, 1975, 1988; Vogel, 1994; Scalera, 1998, 2005a, 2006; Maxlow, 2002, 2012).

The sea-floor magnetic stripes ensure an excellent degree of confidence on post-Triassic oceanic crustal accretion rates and radical expansionists immediately converted the ocean expansion to the Earth inflation rate. The resulting Early Jurassic Earth diameter was 6600 km (Vogel, 1994; Scalera, 1998, 2005b, 2006; Maxlow, 2002, 2012), meaning that our planet had almost doubled its diameter in about 200 Myr (Figs. 2, 3). If the same rate of expansion $(6600 \mathrm{~km}$ in $200 \mathrm{Myr}$ ) were linearly extrapolated backwards in time, the whole planet would not have existed before the Devonian (Fig. 3). Therefore, the various opinions among expansion- ists about the growth rate of the planet abandoned the option of a linear expansion in order to converge on the idea that Earth inflation followed an exponential trend.

Indeed, the pattern of the sea-floor magnetic striping provides the most striking evidence disproving Earth inflation (Fig. 1). Magnetic anomalies (Bird et al., 2007; Korhonen et al., 2007) and age (Heezen and Fornari, 1975; Mueller et al., 1993) maps of the ocean floors show that the ocean basins generated by the fragmentation of Pangea (Atlantic, Indian, and Southern oceans) are axially symmetrical. Every MidOcean Ridge (MOR) runs along the geographical mid-ocean line, and divides two symmetrical sequences of parallel magnetic stripes of gradually increasing age from the MOR to the continent-ocean transition. Theoretically the symmetrical oceanic expansion could, of course, agree with both a constant-size planet, given that older crust is removed when new crust is added, and an inflating planet if subduction does not happen.

Furthermore, in the Pacific Ocean the MOR is the symmetrical spreading axis of two opposite sequences of magnetic stripes, so much so that the first magnetic profiles from the southern Pacific Ocean (Pitman and Heirtzler, 1966; Herzilier et al., 1968) were the most strikingly symmetrical ever recorded worldwide. However, the opposite continental margins of the Pacific Ocean do not fit together, although the complex arrangement of archipelagos, islands and peninsulas along the Asian coast can give plenty of opportunities for ad hoc adjustments (Fig. 1). Moreover, the East Pacific MOR runs very close to the American coast, terminating against the North American continental margin. The Chile Ridge forms a triple junction with the East Pacific Ridge, and terminates against the coast of South America. Finally, the MOR between Cocos and Nazca plates ends against Central America. If Earth were expanding, the abrupt terminations of ocean ridges against the continental margins would not be possible, because they should instead cross another transversely spreading ridge. For this reason, Carey (1983b, 1988) stated that mountain ranges are a different type of expanding ridge. Moreover, oceanic crust older than $50 \mathrm{Ma}$ is missing along the American side of the Pacific Ocean, while along the Asian coast ocean crust dating to $180 \mathrm{Ma}$ is largely preserved. Plate tectonics explains the missing oceanic crust through destruction via subduction at convergent plate boundaries, the asymmetric magnetic bands offshore California, and the ridge truncations (Anderson, 1971). The expansion theory is instead unable to explain how new oceanic crust could preferentially accrete along only one side of a MOR, or how expanding ridges could terminate against convergent margins.

Another characteristic feature of oceanic plates is the transform faults running from the MOR to the continental margins, parallel to the spreading direction (Menard, 1969). These structures have a dominantly vertical displacement, although they might also have a lateral component along strike and allow the rigid lithospheric plates to adjust to the 


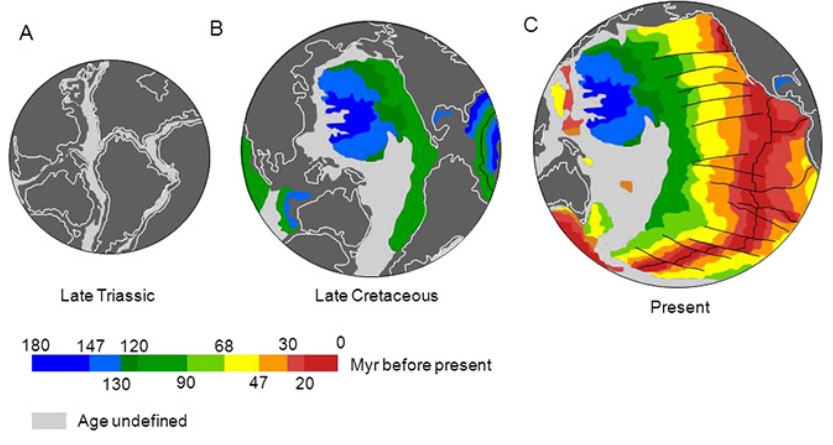

Figure 1. Planetary expansion, Pacific Ocean view, redrawn from McCarthey (2003, 2005b). (A) Late Triassic “dwarf Earth". Following expansionist reconstructions all the world oceans, including the Pacific Ocean, are closed, and opposite continental shelves are in direct connection on a whole-continental-crust planet. The light-grey areas of undefined age may be deep-water seas, although the central Atlantic did not exist in the Triassic. South America nests inside the Gulf of Mexico, distorting the Florida peninsula and removing the Yucatan to achieve a proper fit. It should be noted that according to Scalera (2007a) the restoration presented by McCarthey (2003, 2005b) is inconsistent. (B) Late Cretaceous dwarf Earth. The onesided spreading of the Pacific Ocean is evident, with the spreading ridge supposedly coincident with the Pacific coast of the Americas. On the right is visible a section of the central Atlantic, showing a symmetrical spreading. The wide expanse of Jurassic Pacific Ocean (blue shades) implies that until the Cretaceous, North America and Asia drifted away from each other while South America remained connected to Australia and Siberia to Alaska. (C) Present-day Earth, showing the general asymmetry of the Pacific Ocean. McCarthey (2003, 2005b) does not provide his estimate for the radius of the Triassic dwarf Earth, but if it is scaled to the present-day Earth, its radius was $67 \%$ of its actual length, significantly larger than estimates from other expansionists.

spherical surface of Earth, isolating adjacent sections with different spreading rates within the same oceanic plate (Wilson, 1965; Morgan 1968). As Carey (1983b) explained, if Earth were expanding, the crust should break with a radial pattern while the surface inflates, generating an arrangement of equidimensional plates resembling shrinkage cracks, or polygonal soils. Transform faults are weak lineaments within the plates, and they would be preferential areas where distension should act if the crust stretches under the push of the inflating Earth and plate margins radially recede from each other. Therefore, on an expanding planet, where the distensional component would largely dominate, a rift would develop instead of a transform fault, creating a network of expanding ridges connected by triple junctions (Fig. 4).

\section{Physical consequences of an expanding planet}

If Earth were expanding, there would be dramatic physical consequences: if the mass of the planet increased with its volume, a way to increase the mass must be found; if the mass remained constant while the volume increased, then there is the problem of explaining the consequent density change. Of course, variations in volume, mass and density will also change the planet's gravitational acceleration at its surface, with effects on atmosphere, hydrosphere and biosphere, and on other objects in space, the most affected being the Moon.

If Earth's mass has remained constant, and it was compressed in a planet with half of Earth's radius (Table 1), the average density would be nearly $40 \mathrm{~g} \mathrm{~cm}^{-3}$. Moreover, the Archean volume of an expanding Earth should have been even smaller than the one at $200 \mathrm{Myr}$. As mentioned before, expansionists mainly support an exponential trend of Earth expansion. Estimates for the post-Triassic time use the oceans' spreading rates derived from ocean floor magnetic anomalies, but those for the preceding $98 \%$ of Earth's history depend on accretion rates of the continental crust. The decreasing resolution of radiometric dating with increasing rock age and problems of the preservation of ancient rocks and accessibility due to erosion, metamorphic recycling and burial would of course complicate the restoration. If the simple assumption is made that Earth's radius has doubled every $200 \mathrm{Myr}$, primordial Earth at its formation, $4.5 \mathrm{Gyr}$ ago, would have had a radius of just a few meters. Therefore, the expansionists had to find an initial planetary size that could fit the supposed exponential trend without giving too unrealistic outcomes. Maxlow $(2002,2012)$ used a global map of the world to calculate the size of Archean Earth, removing continental sediments and crystalline rocks of increasing age. Although this is a largely questionable approach, because it groups, in the same cluster, rocks formed during time intervals spanning about $2 \mathrm{Gyr}$, Maxlow $(2002,2012)$ estimates an initial Earth radius of $1700 \mathrm{~km}$, almost equivalent to the radius of the Moon or slightly larger than Earth's inner core (Fig. 2). This is the smaller primordial-Earth radius proposed by the expansionists and, because of the supposed exponential expansion trend, lasted for $3.5 \mathrm{Gyr}$, until the Neoproterozoic. In the case of the $1700 \mathrm{~km}$ Archean radius of Maxlow (2002, 2012), Earth's density would have been $290 \mathrm{~g} \mathrm{~cm}^{-3}$.

Earth's surface gravity would also be higher if the planet's mass were compacted into a smaller volume: if Earth's mass were concentrated in half of its present diameter, the surface gravitational acceleration $200 \mathrm{Myr}$ ago would have been $36.6 \mathrm{~m} \mathrm{~s}^{-2}$. The surface gravity of a $1700 \mathrm{~km}$ radius Earth would be $138 \mathrm{~m} \mathrm{~s}^{-2}$. Even expansionists find these figures unlikely, so they claim that, when Earth was smaller, its mass was also lower and somehow increased together with the increasing volume. This could have happened following two very different patterns: Earth's mass has increased with size but the average density has remained constant, and therefore the surface gravity has increased, or the average density of the planet decreased while its mass increased and the surface gravity remained constant (Table 1, Fig. 3).

If a planet has the same density as Earth but only half its radius (Fig. 3), the surface gravitational acceleration would be only $5 \mathrm{~m} \mathrm{~s}^{-2}$, slightly higher than those of Mars or Mercury, 
Table 1. Physical parameters of Earth (first line) compared to the Moon, the internal planets of the solar system, and different scenarios of "dwarf Earth", with one of the planetary parameters (in brackets) maintained equal to present-day Earth values through the hypothetical planetary expansion. J1, J2, J3: Early Jurassic dwarf Earth with $6600 \mathrm{~km}$ diameter, where mass, density and surface gravity, respectively, have been kept constant. A1, A2 and A3: Archean (4500 Ma) dwarf Earth with size according to Maxlow (2001, 2002, 2012), where mass, density and surface gravity, respectively, have been kept constant. In brackets are the planetary parameters left constant in each scenario. Although Mercury's size comparable to Mars and the Moon, its average density is close to that of Venus and Earth because of the large size of its metallic core.

\begin{tabular}{lrrrrrr}
\hline & $\begin{array}{r}\text { Diameter } \\
\mathrm{km}\end{array}$ & $\begin{array}{r}\text { Surface area } \\
\times 10^{12} \mathrm{~m}^{2}\end{array}$ & $\begin{array}{r}\text { Volume } \\
\times 10^{19} \mathrm{~m}^{3}\end{array}$ & $\begin{array}{r}\text { Mass } \\
\times 10^{22} \mathrm{~kg}\end{array}$ & $\begin{array}{r}\text { Density } \\
\mathrm{g} \mathrm{cm}^{-3}\end{array}$ & $\begin{array}{r}\text { Surface gravity } \\
\mathrm{m} \mathrm{s}^{-2}\end{array}$ \\
\hline Earth & 12742 & 510 & 108 & 597 & 5.5 & 9.8 \\
Mercury & 4880 & 75 & 6 & 33 & 5.4 & 3.9 \\
Venus & 12102 & 460 & 93 & 487 & 5.2 & 8.8 \\
Mars & 6800 & 145 & 16 & 64 & 3.9 & 3.9 \\
Moon & 3476 & 38 & 2 & 7 & 3.3 & 1.6 \\
$\mathrm{~J} 1$ & 6600 & 137 & 15 & {$[597]$} & 39.7 & 36.6 \\
$\mathrm{~J} 2$ & 6600 & 137 & 15 & 83 & {$[5.5]$} & 5.1 \\
$\mathrm{~J} 3$ & 6600 & 137 & 15 & 160 & 10.6 & {$[9.8]$} \\
$\mathrm{A} 1$ & 3400 & 36 & 2 & {$[597]$} & 290.4 & 138.0 \\
A2 & 3400 & 36 & 2 & 11 & {$[5.5]$} & 2.6 \\
$\mathrm{~A} 3$ & 3400 & 36 & 2 & 42 & 20.7 & {$[9.8]$} \\
\hline
\end{tabular}
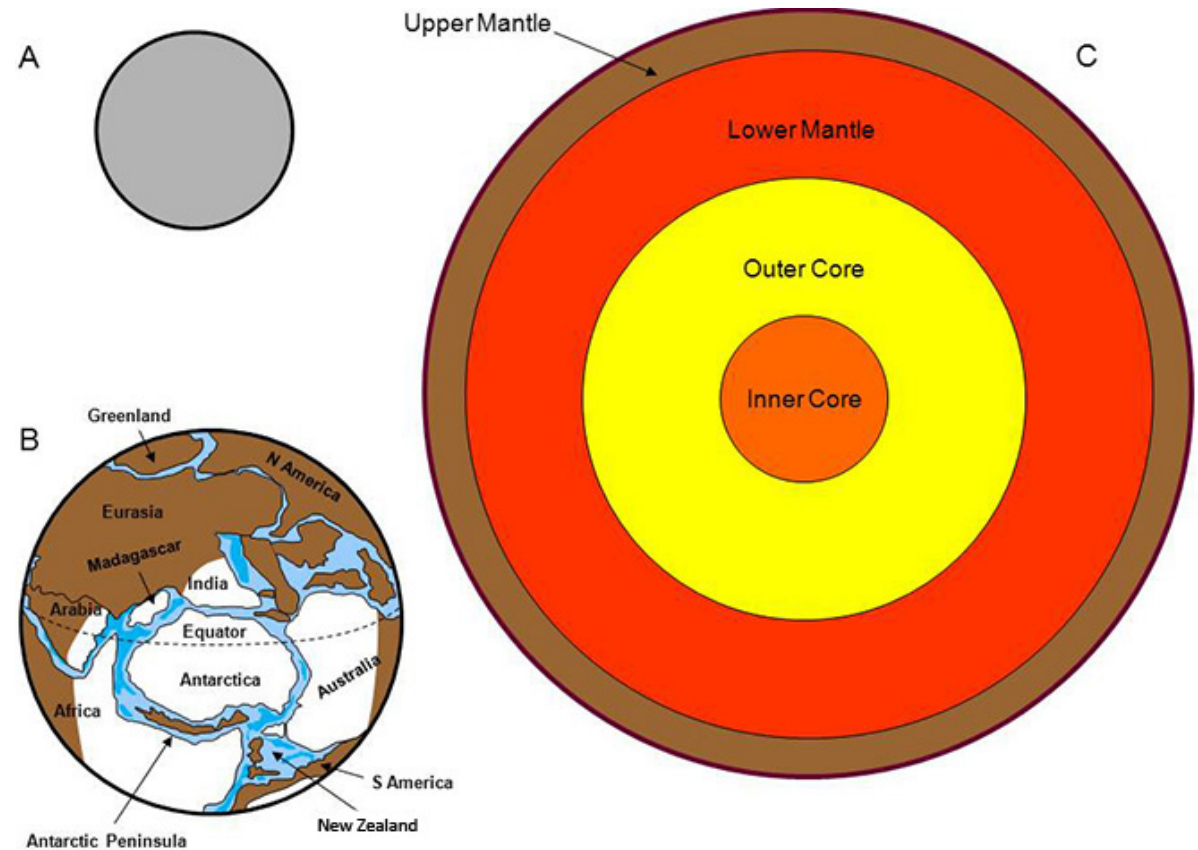

Figure 2. (A) $1700 \mathrm{~km}$ radius Archean dwarf Earth of Maxlow (2002, 2012). (B) $3300 \mathrm{~km}$ radius Late Triassic dwarf Earth from Maxlow (2002, 2011, 2012) and Scalera (2003b, 2005b, 2006, 2007a). (C) The internal structure of Earth. All planets are drawn at the same scale. The paleogeographic restoration in (B) is based on Scalera (2006, 2005b, 2007a). Scalera (2006, 2007a) does not provide a color scheme, but brown most likely indicates emerged areas, light blue shallow seas, and dark blue deep water. The white areas, which are not in the original images of Scalera $(2006,2007 \mathrm{a})$ and Maxlow $(2011,2012)$, indicate the areas covered by the Permo-Carbonifeorus ice cap in standard paleogeographic maps. New Zealand and the Antarctic Peninsula were free of ice cover because they were submerged or outside of the glaciated areas. The ice cap also did not reach the western side of South America. If the expansionist interpretation were correct, the ice cap would have extended across the Equator, unless the whole planet had shifted its rotational axis from the Carboniferous to the Triassic. Moreover, if Pangea completely enveloped the planet, remains of a second ice cap should exist on land masses on the opposite pole. Extension of epicontinental seas notoriously varied in Earth's history, but during the Permo-Triassic they covered a limited fraction of Pangea; therefore, the expansionist dwarf Earth in the Late Triassic should have been mainly emerged, with isolated sea basins, as it is also shown in Scalera $(2006,2007 a)$. 


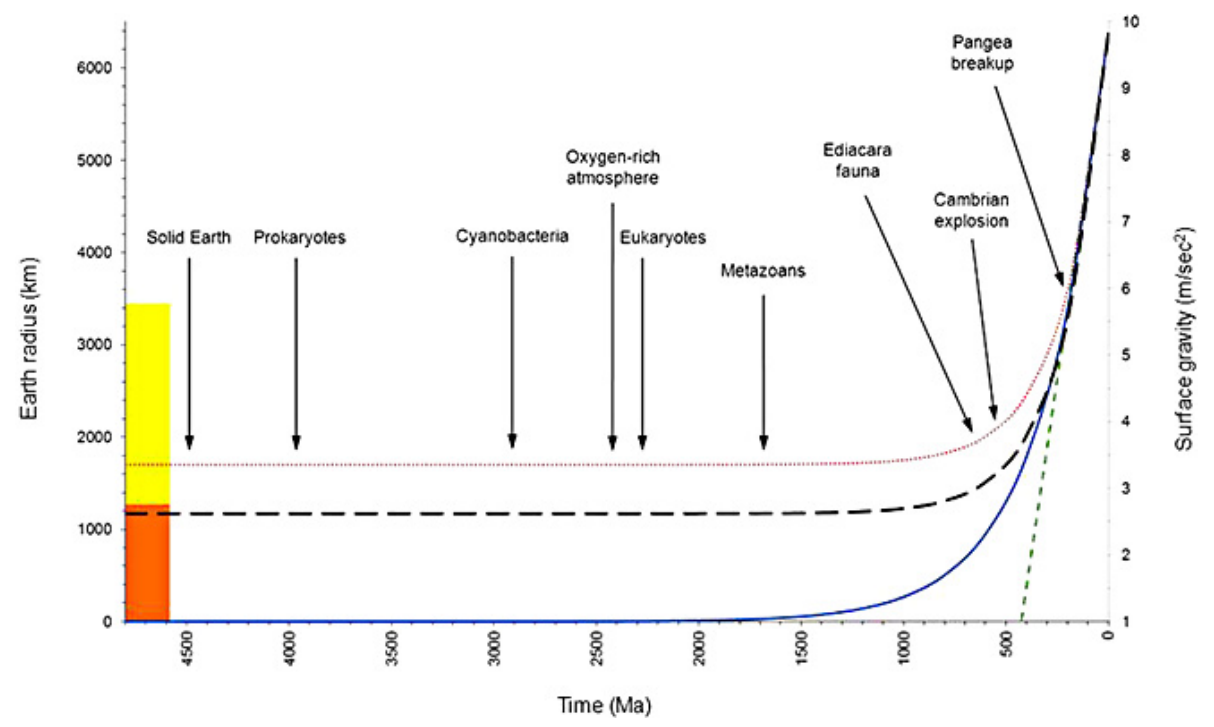

Figure 3. Variations in the planetary radius and surface gravity of an Earth expanding its size through time according to different scenarios. Major events in Earth's history are indicated at the relative time of occurrence. The orange and yellow blocks on left-hand side correspond to the radial extensions of Earth's inner core and outer core, respectively. Short-dashed line: linear trend of planetary expansion extrapolated by post-Triassic oceanic expansion $(3300 \mathrm{~km} / 200 \mathrm{Myr})$. Solid line: exponential trend of planetary expansion extrapolated by halving Earth's diameter every $200 \mathrm{Myr}$. Dotted line: exponential trend of planetary expansion calculated using the formula from Maxlow (2012). Longdashed line: Earth's surface gravitational acceleration with increasing planetary radius following the exponential trend of Maxlow (2012) if a constant average density of $5.5 \mathrm{~g} \mathrm{~cm}^{-3}$ during expansion is hypothesized. Crucial events in Earth's history should have happened in reduced gravity, similar to the gravity of Mercury or Mars.

A

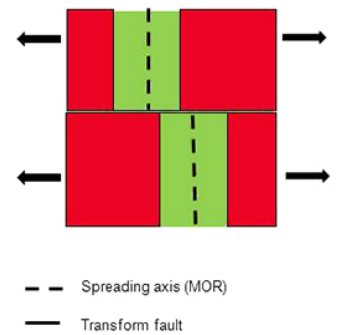

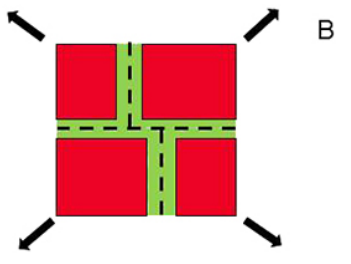

- - Spreading axis (MOR)

Figure 4. (A) Transform faults on a constant-size planet divide adjacent sections of the same oceanic plate expanding at different speeds. (B) On an expanding planet, every plate recedes from the adjacent ones, increasing the distance by moving radially. Therefore, no transform fault is needed to accommodate differential spreading rates, and a network of triple junctions and connecting spreading ridges would surround equidimensional plates.

which have an extremely thin atmosphere and no liquid water (Lammer et al., 2008). The $1700 \mathrm{~km}$ radius Archean Earth of Maxlow $(2002,2012)$ has almost the same size of the Moon, and its gravity would be about $2.6 \mathrm{~m} \mathrm{~s}^{-2}$ : the possibility that such a small gravitational force could retain any atmosphere at all is negligible and clearly disproved by analogue objects in the solar system. It is also very unlikely that the Moon would have orbited Earth if our planet had such a low gravity. Moreover, following the trend of Maxlow (2012), the $1700 \mathrm{~km}$ radius Earth lasted until the Neopro-

terozoic ( $1 \mathrm{Ga})$ and the "dwarf Earth" did not reach the size of Mercury, and a surface gravity of $3.8 \mathrm{~m} \mathrm{~s}^{-2}$, before the Devonian. Then, if a constant density is postulated through the supposed Earth inflation, conditions were of extremely reduced gravity and there was only a minimal atmosphere for at least $90 \%$ of the planet's existence. However, crucial events in Earth's history, like the formation and retention of the atmosphere, the accumulation of liquid water on surface, the evolution of life, of the eukaryotic cells, the development of metazoans and vertebrates, and many geological data require physical conditions similar to those of the present day to have persisted for almost the entire history of our planet (Margulis and Lovelock, 1974; Kasting, 1993; Allègre and Schneider, 1994; Mojzsis et al., 1996; Anbar et al., 2001; Wilde et al., 2001; Fedonkin, 2003; Lunine, 2006; Netman et al., 2007; Schopf et al., 2007; Nystuen et al., 2008; El Albani et al., 2010; Hickman and Van Kranendonk, 2012; Van Kranendonk et al., 2012). Therefore the hypothetical dwarf Earth should have maintained almost the same surface gravity as present-day Earth.

From the discussion above it is clear that a dwarf Earth could have the same surface gravity as the actual Earth only if it is denser than our planet (Table 1). For a $3300 \mathrm{~km}$ radius Earth the minimum average density is close to $11 \mathrm{~g} \mathrm{~cm}^{-3}$. Exoplanets of similar or higher density are currently modeled and have possibly been detected (Seager et al., 2007), but this dwarf Earth would entirely consist of the metallic 
core, without any silicates to form the crust and mantle. Such a Mars-size, full-metal object has no equivalent in the entire solar system, although Mercury could represent the closest example of a planet largely consisting of metal, because its iron core makes up a large part of its volume and mass (Harder and Schubert, 2001). However, this is unusual compared to other terrestrial planets and it is not believed that Mercury originally formed with a higher metallic component, but that it has lost a large fraction of its original mantle because of collisional erosion (Rubie et al., 2007). Of course, it should be considered that the $3300 \mathrm{~km}$ radius dwarf Earth is only an intermediate step from an even smaller dwarf Earth. The $1700 \mathrm{~km}$ radius Earth of Maxlow (2002, 2012), which should have lasted for about $80 \%$ of Earth's history, would require an average density of $21 \mathrm{~g} \mathrm{~cm}^{-3}$, higher than the density of Earth's inner core, to have the same surface gravity of Earth. Moreover, the inexplicable average density transition from 21 to $5.5 \mathrm{~g} \mathrm{~cm}^{-3}$ should have been fine-tuned in relation to the size change to maintain a constant gravity. Finally, it should be considered that even if the dwarf Earth had the same surface gravity of the actual Earth, this does not mean that the gravitational force is the same for the two planets because, although denser, the dwarf Earth has a much lower mass than the real Earth and therefore generates a lower gravitational force. This means that the Moon could not have maintained its orbit around Earth.

The physical parameters of a dwarf Earth also conflict with our knowledge of Earth's internal structure. Like all other planets, Earth consists of concentric layers characterized by different density, composition and physical state. Below the thin outer shell of the crust, the solid silicate mantle is further divided into layers of different mineralogical composition because different minerals are stable at different pressures and temperatures (Fig. 2). The inner core is solid, but consisting of an iron alloy with nickel and some lighter elements, while the outer core is liquid because its temperature is higher than the melting point for the same iron alloy at the pressure existing at that depth. This internal structure of Earth formed because the energy released by impacts with other planetoids partially melted the undifferentiated Earth. Immiscible liquids segregated in the molten mass and the liquid iron accumulated towards the bottom of the lava ocean, and then moving further down towards the center of the planet, displacing the lighter elements that migrated towards the surface, finally forming separate concentric layers via gravitational differentiation (Rubie et al., 2007).

Assuming that the supposed dwarf Earth developed as Earth evolved, from the aggregation of planetesimals followed by partial melting due to impacts and finally internal differentiation, the existence of the outer liquid core is problematic. As mentioned above, the Archean dwarf Earth of Maxlow $(2002,2012)$ is only a little larger than Earth's inner core, while the Late Triassic dwarf Earth is slightly larger than Earth's outer core. If the Archean dwarf Earth already had a liquid outer core, this must have opportunely increased its thickness and internal radius while the planet inflated, although it is questionable whether an iron alloy could exist in a liquid phase in a high-density object like the dwarf Earth. On the other hand, if the original dwarf Earth had no liquid outer core, this must have appeared at some stage of the planet's expansion, possibly after the dwarf Earth had reached a size larger than the one of Earth's core. Given the timing of the planetary inflation suggested by the expansionists, the liquid outer core must have suddenly appeared or rapidly expanded within just a few million years. At the same time, the mantle mineralogical layering should have also rapidly formed and radially expanded or shifted while the planetary size and mass increased. This rapid planetary differentiation and evolution is contradicted by our understanding of Earth's interior. Integration of seismic data, thermodynamic models, laboratory experiments, and analysis of xenoliths and xenocrystals provide an increasingly accurate picture of the deep Earth, its physical and temperature conditions, internal dynamics, chemical composition and stability phases at different depths (Saxena, 2010). Although different models could fit the same set of data, the range of variations is strictly constrained and leaves no room for a smooth (i.e., non-catastrophic) planetary expansion.

The expansionist hypothesis also has implications conflicting with Earth's thermal history. Although the decay of radioactive elements increases Earth's internal temperature, and short-lived radioactive elements might have been an important source of internal heat, the impacts were the major contributor to the internal thermal energy of the planet (England et al., 2007; Rubie et al., 2007). Therefore, if the expansionist dwarf Earth formed as the actual Earth did, the initial thermal energy accumulated by the smaller mass planet would have been lower than that of the full-sized Earth, and it would have largely dissipated during the extensive length of time the dwarf Earth maintained an almost constant size (Fig. 3). A different source of internal heat, able to increase the internal temperature of the inflating planet to the point of melting the outer core, must be found. This heat source must have also not been active until the planet had appreciably increased its size, or the dwarf Earth would have probably never solidified.

\section{Exotic physics for an expanding planet}

Several different mechanisms have been proposed over the years to explain the supposed planetary expansion, but even Carey (1975), listing the existing expansion theories, commented that none of them was convincing, and expansionists are still discussing the same wide range of solutions today (Scalera, 2003b; Maxlow, 2012). Expansionists have not been deterred by their inability to offer a plausible expanding mechanism; instead their failure in finding an explanation within the accepted physical laws had the effect of increasing their reliance on pseudoscientific solutions. 
Possible mechanisms suggested for the growth of planetary volume and mass are the aggregation of material from space, or the generation of new material inside the planet. The accretion of cosmic material might seem at first a reasonable hypothesis for planetary mass growth. All bodies in the solar system formed by the aggregation of gas and dust in the primitive solar nebula, and extraterrestrial material is constantly falling on Earth (Bland et al., 1996; PeuckerEhrenbrink, 1996; Karner et al., 2003; Yada et al., 2004; Zolensky, 2006), sometimes with very dramatic effects (Alvarez et al., 1980; French, 1998; Chapman, 2004). However, during the formation of the solar system, the growing planets cleaned their orbits of residual material and, when the Sun reached the necessary mass to trigger nuclear fusion reactions, the solar wind expelled what remained of the original cloud (Taylor, 2001; Righter and O'Brien, 2011). Clearly, the bulk of mass growth of the Sun and the planets must have occurred early in the life of the solar system, leaving only little material for further accretion, in striking contrast with the possibility of an exponential growth. Moreover, since the material rains down from space like a snowfall, the Jurassic crust should be buried below thousands of kilometers of younger rocks.

The alternative hypothesis is that new mass is continuously generated inside the planet (Carey, 1988; Edwards, 2006; Betelev, 2009). This idea could find support in the hypothesis of Hoyle (1948) and Hoyle et al. (1993) that new matter is being created in the universe to sustain the model of a steady-state universe. Not only has evidence of this process never been found but the cosmic microwave background radiation discovered by Penzias and Wilson (1965) is considered crucial proof against a steady-state universe (Smoot, 2006). However, even if the hypothesis of Hoyle (1948) and Hoyle et al. (1993) were confirmed, further problems would arise. Any new matter generated in the universe must be in the form of elementary particles: as Hoyle (1948) explained, magnetic neutrality of the universe requires that newly generated particles be neutrons; therefore the neutrons must somehow combine to generate the various elements. However, nucleosynthesis of light elements $(\mathrm{H}, \mathrm{He}, \mathrm{Li}, \mathrm{Be})$ occurred within seconds to minutes of the Big Bang at hightemperature, high-density conditions not existing anywhere in the universe today, while the nucleosynthesis of heavier elements can only happen inside stars and during supernova explosions through processes requiring physical conditions not existing inside planets (Wallerstein et al., 1997). Moreover, even if newly created neutrons could possibly emerge inside Earth, they would soon decay to protons and electrons with emission of antineutrinos. If the neutrons were captured by preexisting elements, the resulting unstable isotopes would also decay, emitting antineutrinos. The geoneutrino flux is currently measured in various underground laboratories worldwide with the aim of measuring the amount and distribution of heat-producing radioactive elements, and the results of these experiments agree with a reference Earth model based on standard geophysical theories (Dye et al., 2008; Huang et al., 2013). According to Scalera (2003b) the rate of new matter generated inside Earth since the Early Jurassic is $1.37 \times 10^{16} \mathrm{~kg} \mathrm{yr}^{-1}$, while, according to Betelev (2009), the rate of mass increase is $5 \times 10^{15} \mathrm{~kg} \mathrm{yr}^{-1}$, and the bulk of this mass will emit antineutrinos within a very short time of its appearance. Huang et al. (2013), in their reference model of heat-producing elements, estimate the amount of $\mathrm{U}$, $\mathrm{Th}$ and $\mathrm{K}$ radioactive isotopes in the planet to be $5 \times 10^{15} \mathrm{~kg}$. Considering the half-life of $\mathrm{U}$, Th and $\mathrm{K}$, only a fraction of this mass decays every year, emitting antineutrinos. Undoubtedly, the geoneutrino flux emitted by the supposed annual increment of Earth's mass would largely exceed the flux due to the decay of radioactive elements, and the geoneutrino detectors would not have missed this contribution.

Expansionists also suggest that the gravitational constant decreased over time (Shneiderov, 1943; Jordan, 1966, 1973; Blake 1978; Yabushita, 1982; Scalera, 2003b; Völgyesi, 2006), an idea already proposed by Dirac (1937, 1938). Therefore, even if Earth has increased in mass over time, the gravitational force would remain almost constant. This was a likely assumption before the discovery of the ocean magnetic striping and the large-scale magnetostratigraphic correlations, when expansionists still favored a slow and linear Earth expansion. As mentioned above, the systematic determinations of the oceans crustal ages, and the magnetic striping correlations at the oceanic scale, clearly indicate that no in situ oceanic crust older than the Early Jurassic is preserved; therefore the expansionists faced the possibility that the planet's radius rapidly extended by $3300 \mathrm{~km}$ in about $200 \mathrm{Myr}$ and the idea of an exponential expansion was introduced. Apart from the inconvenience that, despite the large number of measurements made, evidence of any change of the gravitational constant has not been found, the variation of the gravitational constant should have followed the same exponential trend of the planet size, and this would have had detectable effects on the entire universe.

\section{Biogeographical correlations and geological lineaments}

The idea of planetary expansion is not restricted to a limited group of heterodox Earth scientists, because it has won the support of at least some biogeographers. According to Ager (1986), Glasby (1999), McCarthy (2003, 2005a, b, 2006, 2007), McCarthy et al. (2007) and Scalera (2007a), a direct connection between the opposite American and Asian coasts could explain some cross-Pacific biogeographical correlations. Removing the Tethys Ocean in a smaller planet should also solve uncertainties about the size and position of India during the Mesozoic and explain evidence of faunal connections between continents divided by the Tethys (Patterson and Owen, 1991; McCarthy, 2005a, b). These biogeographical problems have been addressed using various 
traditional approaches (Hallam, 1986; Stanley, 1994; Holloway and Hall, 1998; Briggs, 1989; Sanmartín and Ronquist, 2004; Sanmartín et al., 2006; Ali and Aitchison, 2008; Noonan and Sites, 2010; Goswami et al., 2011; van Hinsbergen et al., 2012), and the expansionist claims have been already refuted in various papers (Thewissen and McKenna, 1992; Briggs, 2004, 2006; Ali, 2006; Ali and Aitchison, 2008). However, this case probably merits some further consideration because, as expansionists like to remember, although biogeographic correlations were probably the clearest evidence supporting ancient continental connections (Wegener, 1924), contemporary geologists and paleontologists still persisted in denying mobilism. Once more it appears that expansionists tend to concentrate on small discrepancies, which seem to be solved by the expansionist solution, but fail to see the much larger consequences generated by their explanation.

According to expansionism, continents entirely covered the surface of Earth from the Archean to the Late Triassic (Figs. 1 and 2); the Atlantic, Indian and Southern oceans did not exist before the Pangean break up; the Pacific Ocean formed in the Early Jurassic; and the Tethys Ocean was a narrow epicontinental sea. The expansionist paleogeographic reconstruction has radical implications: geologic record indicates that the global sea level was especially low during the Permo-Triassic, continental conditions prevailed across Pangea, and epicontinental seas had limited extension. Therefore, the sea surface in the supposed Permo-Triassic dwarf Earth had lower extension than land areas. It is likely that the sea-to-land ratio in pre-Permian expansionist dwarf Earth was similar to the Permian figure, because although the area covered by epicontinental seas widely changed during Earth's history, most of the sea areas on Earth belong to ocean basins and expansionists claim that no oceans existed before the Early Jurassic. On modern Earth, water covers $70 \%$ of the planet's surface, but submerged continental shelves represent only $10 \%$ of the planet's surface. Removing all oceans, and recalculating the percentages for a wholecontinental-crust planet, land would cover $75 \%$ of the surface, leaving only $25 \%$ as sea. A similar arrangement should have provided opportunity for the most extensive homogenization of the terrestrial ecosystems, allowing easy migration pathways for land animals and vegetation. However, against the very limited number of apparently anomalous trans-Pacific connections, the bulk of the fossil record allows ancient biogeographic zones and migration barriers to be identified. On the other hand, if the land areas were more extended than seas, marine biota should have been isolated in unconnected epeiric seas, while the fossil record indicates that there was no such segregation. A low sea/land ratio also has implications for the climate and marine circulation of the dwarf Earth and it is not compatible with current understanding of pre-Permian reciprocal positions of continents (Torsvik et al., 2002; Cocks and Torsvik, 2006).
Once the supposed inflation accelerated the expansion of Earth at the end of the Triassic, the Gondwanan continents broke off from Laurasia and rapidly moved away from each other, but India and Australia remained attached or very close to Asia. Therefore, the present-day narrow link between Southeast Asia and Australia through the Indonesian archipelago would only be the vanishing thread left from a formerly extended connection involving Australia, Southeast Asia, India and South America. However, there is no indication that Australia and Asia ever shared a similar fauna in the past, and today the Wallace Line (Wallace, 1876; Moss and Wilson, 1998) still divides the radically different Asiatic and Australian biogeographic regions. Expansionists might claim that the Tethys epicontinental sea divided India from Asia, preventing faunal and floral exchange, but there are several very well documented examples of long-range migrations between continents isolated by continental seas. The Proboscidea dispersed from Africa to all other continents (Australia, remarkably, not included), the Camelidae dispersed from North America to South America, Eurasia and Africa (again, not Australia until British colonization), and the Equidae repeatedly migrated from North America to Eurasia and Africa. Moreover, the Pleistocene Great American Interchange (Marshall, 1988) shows that rapid and massive migrations can occur across long latitudinal distances and different climatic zones, and the separation of India from surrounding continents did not apparently prevent faunal interchange (Briggs, 1989).

Therefore, to explain the controversial trans-Pacific correlations following the expansionists's approach, biogeographers need not only abandon a well-supported geodynamic model to embrace a theory that violates basic physical laws and rejects traditional explanations that are considered valid in many other occasions, but they must also neglect the existence of the most striking biogeographical boundary on the entire planet dividing regions that, according to the inflation theory, were in direct contact for billions of years. They must also discard all pre-Permian biogeographical data, which could not fit a model where all continents are reciprocally connected and never changed their relative positions.

\section{Conclusions}

Science is an essentially anarchist enterprise, and many irrational motivations can concur in a theory's success or failure (Feyerabend, 1975). Moreover, regardless of the amount of confirming experiments and observations, a scientific theory can always prove wrong (Popper, 1959). On the other side, the theory's supporters could actually decide that contrasting evidence is not actually disproving the theory but just challenging a subordinate part of it (Lakatos, 1978). The observed anomalous precession of Mercury was not believed to be a good reason to abandon Newtonian general gravitation until Einstein's relativity theory showed that Newtonian 
laws do not apply under these specific conditions. Regardless of these limitations, when more data are collected, the increasing constraints decrease the freedom for speculation, helping to discriminate and abandon the theories less efficient in explaining the data (Kuhn, 1962; Lakatos, 1978). The geocentric planetary model could prevail on the heliocentric system for about two millennia, with the late addition of Tycho's geoheliocentric compromise, until the new observations performed by Galilei using the telescope allowed for astronomers to select the model providing the best description of the solar system.

After more than 50 years of competition, and occasional reciprocal influence, between contractionist, expansionist and mobilist geodynamic theories, the discovery of the seafloor magnetic stripes led to the introduction and general adoption of plate tectonics. Since this revolution in the Earth sciences, the persistence of expansionism was only possible because of the systematic rejection of any contrasting data, and the selective adoption of those data that could fit the theory. While expansionists fully accept divergent margins, they deny subduction, although the evidence supporting both margin types are based on the same kind and quality of geological data (earthquakes' magnitude and depth of hypocenters, gravimetric and magnetic anomalies, geothermal gradients, GPS measurements, seismic profiling and metamorphic assemblages). Expansionists also fail to appreciate that the pattern of mid-ocean ridges and magnetic striping on the bottom of the Pacific Ocean is incompatible with planetary expansion. Moreover, expansionist paleogeographic reconstructions fail to explain how, during the Paleozoic, portions of modern continents moved around the planet, rearranging themselves in the most unexpected patterns (Burke et al., 1976; Dalziel et al., 1994; Torsvik, 2003; Meert and Torsvik, 2003).

While expansionists claim that Earth scientists dogmatically follow a theory (plate tectonics) falsified by geological data, they promote or incorporate borderline and pseudoscientific ideas, including generation of new matter inside Earth, variation of cosmic constants, and exotic matter transformations, conflicting with accepted physical theories. Several combinations of these largely unorthodox theories are used as possible explanations of the mechanism of planetary inflation. Despite almost a century of speculation on the various possible mechanisms advocated to explain Earth inflation, expansionists are still unable to select at least one of these hypotheses as a promising line for further investigation. They also admit that, according to current science, many solutions are physically impossible. However, they do not infer from this conclusion that the theory itself might be wrong, but rather that our knowledge of fundamental physics is inadequate and a scientific revolution is needed.

Although the extraordinary results achieved by plate tectonics do not mean that this theory could not be further improved, or that a better geodynamic model could not be found, Earth expansion is clearly not a viable candidate to replace plate tectonics.

Acknowledgements. I would like to express my great appreciation to the topical editor, Pascal Richet, and an anonymous referee for the helpful comments and suggestions they offered after the revision of the original paper. I also wish to acknowledge Sean Farrow for revision of the English text.

Edited by: P. Richet

Reviewed by: V. Deparis and one anonymous referee

\section{References}

Ager, D. V.: Migrating fossils, moving plates and an expanding earth, Modern Geology, 10, 377-390, 1966.

Ali, J. R.: Biogeographical and geological evidence for a smaller, completely-enclosed Pacific basin in the Late Cretaceous: a comment, J. Biogeogr., 33, 1670-1674, 2006.

Ali, J. R. and Aitchison J. C.: Gondwana to Asia: plate tectonics, paleogeography and the biological connectivity of the Indian subcontinent from the Middle Jurassic through latest Eocene (166$35 \mathrm{Ma}$ ), Earth-Sci. Rev., 88, 145-166, 2008.

Allègre, C. J. and Schneider, S. H.: The evolution of the Earth, Sci. Am., 271, 66-75, 1994.

Alvarez, L. W., Alvarez, W., Asaro, F., and Michel, H. V.: Extraterrestrial cause for the Cretaceous-Tertiary extinction, Science, 208, 1095-1108, 1980.

Anbar, A. D., Zahnle, K. J., Arnold, G., and Mojzsis, S. J.: Extraterrestrial iridium, sediment accumulation and the habitability of the early Earth's surface, J. Geophys. Res., 106, 3219-3236, 2001.

Anderson, D.: The San Andreas fault, Sci. Am., 225, 42-66, 1971.

Anonymous: Second circular for the 32nd IGC, 32nd IGC Circulars, 2004.

Anonymous: Fifth and final circular for the 34th IGC, 34th IGC Circulars, 2012.

Asphaug, E., Agnor, C. B., and Williams, Q.: Hit-and-run planetary collisions, Nature, 439, 155-160, 2006.

Badash, 1.: The age-of-the-Earth debate, Sci. Am., 261, 90-96, 1989.

Barnett, C. H.: Oceanic rises in relation to the expanding Earth hypothesis, Nature, 221, 1043-1044, 1969.

Benioff, H.: Orogenesis and deep crustal structure - additional evidence from seismology, Geol. Soc. Am. Bull., 65, 385-400, 1954.

Benioff, H.: Seismic evidence for crustal structure and tectonic activity, Geol. S. Am. S., 62, 61-74, 1955.

Betelev, N. P.: The concept of an expanding Earth, J. Volcanol. Seismol., 3, 355-362, 2009.

Billings, M. P.: Diastrophism and mountain building, Geol. Soc. Am. Bull., 71, 363-398, 1960.

Bird, D. E., Hall, S. A., Burke, K., Casey, J. F., and Sawyer, D. S.: Early Central Atlantic Ocean seafloor spreading history, Geosphere, 3, 282-298, 2007.

Blake, G. M.: The Large Number Hypothesis and the rotation of the Earth, Mon. Not. R. Astron. Soc., 185, 399-407, 1978. 
Bland, P. A., Smith, T. B., Jull, A. J. T., Berry, F. J., Bevan, A. W. R., Cloudt, S., and Pillinger, C. T.: The flux of meteorites to the Earth over the last 50000 years, Mon. Not. R. Astron. Soc., 283, 551-565, 1996.

Briggs J. C.: The historic biogeography of India: isolation or contact?, Syst. Biol., 38, 322-332, 1989.

Briggs, J. C.: The ultimate expanding Earth hypothesis, J. Biogeogr., 31, 855-857, 2004.

Briggs, J. C.: Another expanding Earth paper, J. Biogeogr., 33, 1674-1676, 2006.

Burke, K., Dewey, J. F., and Kidd, W. S. F.: Precambrian palaeomagnetic results compatible with contemporary operation of the Wilson cycle, in: Ancient plate margins, edited by: Briden, J. C., Tectonophysics, 33, 287-299, 1976.

Carey, W. S.: A tectonic approach to continental drift, in: Continental drift, edited by: Carey, S. W., A symposium, University of Tasmania, Hobart, 177-363, 1958.

Carey, W. S.: The Expanding Earth-an essay review, Earth Sci. Rev., 11, 105-143, 1975.

Carey, S. W.: A philosophy of the Earth and universe, Papers and Proceedings of the Royal Society of Tasmania, 112, 5-19, 1978.

Carey, S. W.: The expanding Earth, A symposium, Sidney 1981, University of Tasmania, 1983a.

Carey, W. S.: The necessity of Earth expansion, in: Expanding Earth Symposium, edited by: Carey, W. S., Sidney, 375-393, 1983 b.

Carey, W. S.: Theories of the Earth and the Universe: a history of dogma in the Earth Sciences, Stanford University Press, 1988.

Chapman, C. R.: The hazard of near-Earth asteroid impacts on Earth, Earth Planet. Sci. Lett., 222, 1-15, 2004.

Choi, D. and Storetvedt, K.: 34IGC Brisbane, Theme 37.2 Pursuit of a new geodynamic paradigm, New Concepts in Global Tectonics Newsletter, 63, 112-114, 2012a.

Choi, D. and Storetvedt, K.: 34th International Geological Congress NCGT session report, New Concepts in Global Tectonics Newsletter, 64, 117-119, 2012b.

Cocks, L. R. M. and Torsvik, T. H.: European geography in a global context from the Vendian to the end of the Palaeozoic, in: European lithosphere dynamics, edited by: Gee, D. G. and Stephenson, R. A., Geo. Soc. Mem., 32, 83-95, 2006.

Collinson, D. W. and Runcorn, S. K.: Polar wandering and continental drift: evidence from paleomagnetic observations in the United States, Geol. Soc. Am. Bull., 71, 915-958, 1960.

Condie, K. C. and Kröner, A.: When did plate tectonics begin? Evidence from the geologic record, in: When did plate tectonics begin on planet Earth?, edited by: Condie, K. C. and Pease, V., Geol. S. Am. S., 440, 281-294, 2008.

Creer, K. M.: An expanding Earth?, Nature, 205, 539-544, 1965.

Dalziel, J. D., Dalla Salda, L. H., and Gahagan, L. M.: Paleozoic Laurentia-Gondwana interaction and the origin of the Appalachian-Andean mountain system, Geol. Soc. Am. Bull., 106, 243-252, 1994.

Dana, I. W. D.: A text-book of Geology, 354 pp., Ivison, Blakeman, Taylor, \& Co., New York, 1863.

Dickins, J. M.: Report on the "Theories other than plate tectonics" session at the 30th IGC, Beijing, August, 1996, New Concepts in Global Tectonics Newsletter, 1, 2, 1996.

Dickson, G. O., Pitman III, W. C., and Heirtzler, J. R.: Magnetic anomalies in the South Atlantic and ocean floor spreading, J. Geophys. Res., 73, 2087-2100, 1968.
Dirac, P. A. M.: The cosmological constants, Nature, 139, 323 , 1937.

Dirac, P. A. M.: A New Basis for Cosmology, Proc. Roy. Soc. Lond. A, 165, 199-208, 1938.

Dye, S. T., McDonough, W. F., and Mahoney, J.: Geoneutrino measurements and models investigate deep Earth, Eos, 89, 433-444, 2008.

Edwards, M. R.: Graviton decay without decreasing G: a possible cause of planetary heating, expansion and evolution, Ann. Geophys. Italy, Supp Vol. 49, 501-509, 2006.

El Albani, A., Bengtson, S., Canfield, D. E., Bekker, A., Macchiarelli, R., Mazurier, A., Hammarlund, E. U., Boulvais, P., Dupuy, J.-J., Fontaine, C., Fürsich, F. T., Gauthier-Lafaye, F., Janvier, P., Javaux, E., Ossa Ossa, F., Pierson-Wickmann, A.-C., Riboulleau, Ar., Sardini, P., Vachard, D., Whitehouse, M. and Meunier, A.: Large colonial organisms with coordinated growth in oxygenated environments 2.1 Gyr ago, Nature, 466, 100-105, 2010.

England, P., Molnar, P., and Richter, F.: John Perry's neglected critique of Kelvin's age for the Earth: a missed opportunity in geodynamics, GSA Today, 4-9, 2007.

Fedonkin, M. A.: The origin of the Metazoa in the light of the Proterozoic fossil record, Paleontol. Res., 7, 9-41, 2003.

Feyerabend, P. K.: Against method, 295 pp., New Left Books, London, 1975.

Frankel, H.: The continental drift debate, in: Scientific controversies: case studies in the resolution and closure of disputes in science and technology, edited by: Engelhardt, H. T. and Caplan, A. L., Cambridge University Press, 203-248, 1987.

French, B. M.: Traces of catastrophe: a handbook of shockmetamorphic effects in terrestrial meteorite impact structures, LPI Contribution No. 954, Lunar and Planetary Institute, Houston, 1998.

Furon, R.: Les relations geologiques de I'Afrique et de l'Amerique du Sud (derive des continents et ponts continentaux), Mus. Natl. d'Hist. nat. Arch., 12, 211-215, 1935.

Furon, R.: La paléogéographie, Essai sur l'évolution des continents et des oceans, Payot, 1941.

Glasby, C. J.: The Namanereidinae (Polychaeta: Nereididae). Part 2, Cladistic biogeography, Records of the Australian Museum, Supplement 25, 131-144, 1999.

Goswami, A., Guntupalli, P. V. R., Upchurchb, P., Boyerd, D. M., Seifferte, E. R., Vermaf O., Gheerbrantg, E., and Flynnh, J. J.: A radiation of arboreal basal eutherian mammals beginning in the Late Cretaceous of India, P. Natl. Acad. Sci., 108, 16333-16338, 2011.

Haarmann, E.: Die Oszillations-Theorie: eine Erklärung der Krustenbewebungen von Erde und Mond, 260 pp., Enke Verlag, Stuttgart, 1930.

Hallam, A.: Great geological controversies, 182 pp., Oxford University Press, 1983.

Hallam, A.: The unlikelihood of an expanding Earth, Geol. Mag., 121, 653-655, 1984.

Hallam, A.: Evidence of displaced terranes from Permian to Jurassic faunas around the Pacific margins, J. Geol. Soc. London, 143, 209-216, 1986.

Harder, H., Schubert, G.: Sulfur in Mercury’s core?, Icarus, 151, 118-122, 2001. 
Heezen, B. C.: Géologie sous-marine et déplacements des continents, Colloques Internationales Centre National Recherche Scientifique, 82, Nice-Villefranche, 295-304, 1959.

Heezen, B. C. and Fornari, D. J.: Geological map of the Pacific Ocean, in: Initial reports of the Deep Sea Drilling Project, edited by: Andrews, J. E., Packham, G., and Herring, J., 30, BackPocket Foldouts, 1975.

Heirtzler, J. R., Dickson, G. O., Herron, E. M., Pitman III, W. C., and Le Pichon, X.: Marine magnetic anomalies, geomagnetic field reversals, and motions of the ocean floor and continents, J. Geophys. Res., 73, 2119-2136, 1968.

Hess, H. H.: History of Ocean Basins, in: Petrologic studies: a volume to honor of A. F. Buddington, edited by: Engel, A. E. J., James, H. L., and Leonard, B. F., Geol. Soc. Am., 599-620, 1962.

Hickman, A. H. and Van Kranendonk, M. J.: Early Earth evolution: evidence from the $3.5-1.8 \mathrm{Ga}$ geological history of the Pilbara region of Western Australia, Episodes, 35, 283-297, 2012.

Holloway, J. D. and Hall, R.: SE Asian gelogy and biogeography: an introduction, in: Biogeography and geological evolution of SE Asia, edited by: Hall R. and Holloway J. D., 1-23, Backhuys Publishers, Leiden, 1998.

Holmes, A.: The age of the Earth, 228 pp., Harper, London, 1913.

Holmes, A.: A review of the continental drift hypothesis, Mining Mag., 40, 205-209, 1929.

Holmes, A.: Radioactivity and Earth movements, Transactions of the Geological Society of Glasgow, 18, 559-606, 1931.

Holmes, A.: Principles of physical geology, 1288 pp., Ronald Press, New York, 1965.

Hongzhen, W., Jahn, B., and Shilong, M.: Proceedings of the 30th international Geological Congress, Volume 1, Origin and history of the Earth, 213, 1997.

Hospers, J. and Van Andel, S. I.: Palaeomagnetism and the hypothesis of an expanding Earth, Tectonophysics, 5, 5-24, 1967.

Hoyle, F.: A new model for the expanding Universe, Monthly Notices of the Royal Astronomical Society, 108, 372-382, 1948.

Hoyle, F., Burbidge, G., and Narlikar, J. V.: A quasi-steady state cosmological model with creation of matter, Astrophys. J., 410, 437-457, 1993.

Huang, Y., Chubakov, V., Mantovani, F., Rudnick, R. L., and McDonough, W. F.: A reference Earth model for the heat-producing elements and associated geoneutrino flux, Geochem. Geophy. Geosy., 14, 1-27, 2013.

Joly, J.: Uranium and geology-II, Science, New Series, 28, 737-743, 1908.

Joly, J.: Radioactivity and geology, 287 pp., Constable \& Co., London, 1909.

Joly, J.: The surface history of the Earth, in: On the nature and origin of the Earth's surface structure, edited by: Joly, J. and Poole, J. H. J., Philos. Mag., 5, 1233-1246, 1925.

Jordan, P.: Die Expansion der Erde Folgerungen aus der Diracschen Gravitationshypothese, Die Wissenschaft, 1966.

Jordan, P.: The Expanding Earth, in: The physicist's conception of nature, edited by: Mehra, J., Reidel Publishing Co., Dordrecht, 60-70, 1973.

Karner, D. B., Levine, J. B., Muller, R. A., Asaro, F., Ram, M., and Stolz, R. M.: Extraterrestrial accretion from the GISP2 ice core, Geochim. Cosmochim. Ac., 67, 751-763, 2003.

Kasting, J. F.: Earth's early atmosphere, Science, 259, 920-926, 1993.
Kelvin Lord (William Thomson): On the secular cooling of the Earth, T RSE, 23, 167-169, 1864.

Korhonen, J. V., Faihead, J. D., Hamoudi, M., Lesur, V., Mandea, M., Maus, S., Purucker, M., Ravat, D., Sazonova, T., and Thebault, E.: Magnetic anomaly map of the world, CCGM - CGMW, 2007.

Kuhn, T. S.: The structure of scientific revolutions, 264 pp., University of Chicago Press, 1962.

Lakatos, I.: The methodology of scientific research programmes: philosophical papers volume 1, Cambridge University Press, 1978.

Lammer, H., Kasting, J. F., Chassefière, E., Johnson, R. E., Kulikov, Y. N., and Tian, F.: Atmospheric escape and evolution of terrestrial planets and satellites, Space Sci. Rev., 139, 399-436, 2008.

Lindemann, B.: Kettengebirge, kontinentale Zerspaltung und Erdexpansion, 186 pp., Fischer Verlag, Jena, 1927.

Lunine, J. I.: Physical conditions on the early Earth, Phil. Trans. R. Soc. B, 361, 1721-1731, 2006.

Margulis, L. and Lovelock, J. E.: Biological modulation of the Earth's atmosphere, Icarus, 21, 471-489, 1974.

Marshall, L. G.: Land Mammals and the Great American Interchange, Am. Sci., 76, 380-388, 1988.

Maxlow, J.: Quantification of an Archean to Recant Earth expansion process: a review of current research, New concepts in global tectonics, 22, 13-21, 2002.

Maxlow, J.: Global expansion tectonics. The theory of the increasing gravity, Ettore Majorana Foundation and Centre for Scientific Culture, 37th Interdisciplinary Workshop of the International School of Geophysics Erice, Sicily, Extended Abstracts Book, 69-73, 2011.

Maxlow, J.: Global expansion tectonics: a significant challenge for physics, Proceedings of the NPA, 9, 363-373, 2012.

McCarthy, D.: The trans-Pacific zipper effect: disjunct sister taxa and matching geological outlines that link the Pacific margins, J. Biogeogr., 30, 1545-1561, 2003.

McCarthy, D.: Biogeography and scientific revolutions, The Systematist, 25, 3-12, 2005a.

McCarthy, D.: Biogeographical and geological evidence for a smaller, completely enclosed Pacific basin in the Late Cretaceous, J. Biogeogr., 32, 2161-2177, 2005b.

McCarthy, D.: Explanations for trans-Pacific disjunctions plausible? Empirical tests of radical dispersalist theories, in: Biogeography in a changing world, edited by: Ebach, M. C. and Tangney, R. S., CRC Press, Boca Raton, 177-198, 2006.

McCarthy, D.: Are plate tectonic explanations for trans-Pacific disjunctions plausible? Empirical tests of radical dispersalist theories, in: Biogeography in a changing world, edited by: Ebach, M. C. and Tangney, R. S., Systematics Association special volume, 70, 177-195, 2007.

McCarthy, D., Ebach, M. C., Morrone, J. J., and Parenti, L. R.: An alternative Gondwana: biota links South America, New Zealand and Australia, Biogeografía, 2, 2-12, 2007.

McKenna, M. C.: Holarctic landmass rearrangement, cosmic events, and Cenozoic terrestrial organisms, Annals of the Missouri Botanical Garden, 70, 459-489, 1983.

Menard, H. W.: The deep-ocean floor, Sci. Am., 221, 126-142, 1969. 
Meert, J. G. and Torsvik, T. H.: The making and unmaking of a supercontinent: Rodinia revisited, Tectonophysics, 375, 261-288, 2003.

Mojzsis, S. J., Arrhenius, G., McKeegan, K. D., Harrison, T. M., Nutman, A. P., and Friend, C. R. L.: Evidence for life on Earth by 3800 million years ago, Nature, 384, 55-59, 1996.

Morgan, W. J.: Rises, trenches, great faults, and crustal blocks, J. Geophys. Res., 73, 1959-1982, 1968.

Moss, S. J. and Wilson, M. E. J.: Biogeographic implications of the Tertiary palaeogeographic evolution of Sulawesi and Borneo, in: Biogeography and geological evolution of SE Asia, edited by: Hall, R. and Holloway, J. D., Backhuys Publishers, Leiden, 133163, 1998.

Mueller, R. D., Roest, W. R., Royer, J.-Y., Gahagan, L. M., and Sclater, J. G.: A digital age map of the ocean floor, SIO Reference Series, 93-30, 1993.

Næraa, T., Scherstén, A., Rosing, M. T., Kemp, A. I. S., Hoffmann, J. E., Kokfelt, T. F., and Whitehouse, M. J.: Hafnium isotope evidence for a transition in the dynamics of continental growth 3.2?Gyr ago, Nature, 485, 627-630, 2012.

Netman, A. P., Mojzsis, S. J., and Friend, C. R.: Recognition of $\geq 3850 \mathrm{Ma}$ water-lain sediments in West Greenland and their significance for the early Archean Earth, Geochim. Cosmochim. Ac., 61, 2475-2484, 1997.

Noonan, B. P. and Sites Jr., J. W.: Tracing the origins of iguanid lizards and boine snakes of the Pacific, Am. Nat., 175, 61-72, 2010.

Nystuen, J. P., Andresen, A., Kumpulainen, R. A., and Siedlecka, A.: Neoproterozoic basin evolution in Fennoscandia, East Greenland and Svalbard, Episodes, 31, 35-43, 2008.

Oreskes, N.: The rejection of continental drift, Hist. Stud. Phys. Biol., 18, 311-348, 1988.

Owen, H. G.: Continental displacement and expansion of the Earth during the Mesozoic and Cenozoic, Phil. Trans. R. Soc. A, 281, 223-291, 1976.

Owen, H. G.: Constant dimensions or an expanding Earth, in: The evolving Earth, edited by: Cocks, L. R. M. British Museum (Natural History) and Cambridge University Press, 179-192, 1981.

Owen, H. G.: Ocean-floor spreading evidence of global expansion, in: The expanding Earth, edited by: Carey, S. W., A symposium; Sidney 1981, University of Tasmania, 31-58, 1983.

Patterson, C. and Owen, H. G.: Indian isolation or contact? A response to Briggs. Syst. Biol., 40, 96-100, 1991.

Penzias, A. A. and Wilson, R. W.: A measurement of excess antenna temperature at $4080 \mathrm{Mc} / \mathrm{s}$, Astrophys. J., 142, 419-421, 1965.

Peucker-Ehrenbrink, B.: Accretion of extraterrestrial matter during the last 80 million years and its effect on the marine osmium isotope record, Geochim. Cosmochim. Ac., 60, 3187-3196, 1996.

Pitman III, W. C. and Heirtzler, J. R.: Magnetic anomalies over the Pacific-Antarctic Ridge, Science, 154, 1164-1171, 1966.

Popper, K.: The logic of scientific discovery, 484 pp., Routledge, New York, 1959.

Righter, K. and O'Brien, D. P.: Terrestrial planet formation, P. Natl. Acad. Sci., 108, 19165-19170, 2011.

Rubie, D. C., Nimmo, F., and Melosh, H. J.: Formation of Earth's core, in: Treatise on geophysics Vol. 9: Evolution of the Earth, edited by: Stevenson, D. J., Elsevier, Amsterdam, 51-90, 2007.

Runcorn, S. K.: Paleomagnetic comparisons between Europe and North America, Proc. Geol. Assoc. Canada, 8, 77-85, 1956.
Ruse, M.: What kind of revolution occurred in geology? PSA: Proceedings of the biennial meeting of the Philosophy of Science Association. Volume two: symposia and invited papers, 240-273, 1978.

Sanmartín, I. and Ronquist, F.: Southern hemisphere biogeography inferred by event-based models: plant versus animal patterns, Syst. Biol., 53, 216-243, 2004.

Sanmartín, I., Wanntorp, L., and Winkworth, R. C.: West Wind Drift revisited: testing for directional dispersal in the Southern Hemisphere using event-based tree fitting, J. Biogeogr., 1-19, 2006.

Saxena, S. K.: Thermodynamic modeling of the Earth's interior, Elements, 6, 321-325, 2010.

Scalera, G.: Paleogeographical reconstructions compatible with Earth dilatation, Ann. Geophys. Italy, 41, 819-825, 1998.

Scalera, G.: Samuel Warren Carey, Campbelltown, November 1, 1911 - Hobart, March 2002, Commemorative memoir, in: Why expanding Earth? A book in honour of O.C. Hilgenberg, edited by: Scalera, G. and Jacob, K.-H., INGV, 85-95, $2003 \mathrm{a}$.

Scalera, G.: The expanding Earth: a sound idea for the new millennium, in: Why expanding Earth? A book in honour of O.C. Hilgenberg, edited by: Scalera, G. and Jacob, K.-H., INGV, Rome, 181-232, 2003b.

Scalera, G.: A new interpretation of the Mediterranean arcs: mantle wedge intrusion instead of subduction, Boll. Soc. Geol. Ital., Volume Speciale, 5, 129-147, 2005a.

Scalera, G.: The global paleogeographic reconstruction of the Triassic and the paleoposition of India, GNGTS - Atti del $18^{\circ}$ Convegno Nazionale, 181-232, 2005b.

Scalera, G.: TPW and Polar Motion as due to an asymmetrical Earth expansion, Ann Geophys Italy, Supp., 49, 483-500, 2006.

Scalera, G.: Fossils, frogs, floating islands and expanding Earth in changing-radius cartography. A comment to a discussion on Journal of Biogeography, Ann. Geophys. Italy, 50, 789-798, 2007a.

Scalera, G.: Geodynamics of the Wadati-Benioff zone earthquakes: the 2004 Sumatra earthquake and other great earthquakes, Geofísica Internacional, 46, 19-50, 2007b.

Scalera, G.: Earthquakes, phase chenges, fold belts: from Apennines to a global perspective, GeoActa Special Publication, 3, 25-43, 2010.

Scalera, G., Boschi, E., and Cwojdzinski, S.: The Earth expansion evidence - A challenge for Geology, Geophysics and Astronomy, Selected contributions to the Interdisciplinary Workshop of the 37th International School of Geophysics Erice, Sicily, 2012.

Schopf, J. W., Kudryavtsev, A. B., Czaja, A. D., and Tripathi, A. B.: Evidence of Archean life: stromatolites and microfossils, Precambrian. Res., 158, 141-155, 2007.

Schellart, W. P. and Rawlinson, N.: Convergent plate margin dynamics: new perspectives from structural geology, geophysics and geodynamic modelling, Tectonophysics, 483, 4-19, 2010.

Seager, S., Kuchner, M., Hier-Majumder, C. A., and Militzer, B.: Mass-radius relationships for solid exoplanets, Astrophys. J., 669, 1279-1297, 2007.

Shneiderov, A. J.: The exponential law of gravitation and its effects on seismological and tectonic phenomena, Transactions Am. Geoph. Un., 3, 61-88, 1943.

Simpson, G. G.: Mammals and the nature of continents, Am. J. Sci., 241, 1-31, 1943. 
Smoot III, G. F.: Cosmic Microwave Background Radiation anisotropies: their discovery and utilization, Nobel Lecture, 2006.

Stanley Jr., G. D.: Late Paleozoic and early Mesozoic reef-building organisms and Paleogeography: the Tethyan-North American connection, Cour. Forsch.-Inst. Senckenberg, 172, 69-75, 1994.

Steine, J.: An expanding Earth on the basis of sea-floor spreading and subduction rates, Geology, 5, 313-318, 1977.

Stinner, A.: Calculating the age of the Earth and the Sun, Physics Education, 37, 296-305, 2002.

Suess, E.: The face of the Earth (Das antlitz der Erde), 604 pp., Clarendon Press, Oxford, 1904.

Taylor, S. R.: Solar System evolution: a new perspective, Cambridge University Press, 2001.

Thewissen, J. G. M. and McKenna, M. C.: Paleobiogeography of Indo-Pakistan. A response to Briggs, Patterson, and Owen, Systematic Biology, 41, 248-251, 1992.

Torsvik, T. H.: The Rodinia jigsaw puzzle, Science, 300, 13791381, 2003.

Torsvik, T. H., Carlos, D., Mosar, M., Cocks, L. R. M., and Malme, T.: Global reconstructions and North Atlantic paleogeography 440 Ma to Recent, in: BATLAS —-Mid Norway plate reconstruction atlas with global and Atlantic perspectives, edited by: Eide, E. A., Geological Survey of Norway, Trondheim, 18-39, 2002.

Van Bemmelen, R. W.: On mega-undulations: a new model for the Earth's evolution, Tectonophysics, 3, 83-127, 1966.

Van Hilten, D.: Global expansion and paleomagnetic data, Tectonophysics, 5, 191-210, 1968.

van Hinsbergen, D. J. J., Lippertc, P. C., Dupont-Nivete, G., McQuarrieh, N., Doubrovine, P. V., Spakmani, W., and Torsvik, T. H.: Greater India Basin hypothesis and a two-stage Cenozoic collision between India and Asia, P. Natl. Acad. Sci., 109, 76597664, 2012.

Van Kranendonk, M. J., Altermann, W., Beard, B. L., Hoffman, P. F., Johnson, C. M., Kasting, J. F., Melezhik, V. A., Nutman, A. P., Papineau, D., and Pirajno, F.: A chronostratigraphic division of the Precambrian, in: The Geologic Time Scale, edited by: Gradstein, F. M., Ogg, J. G., Schmitz, M., and Ogg, G., Elsevier B.V., 299-392, 2012.

Vine, F. J.: Spreading of the ocean floor: new evidence, Science, 154, 1405-1415, 1966.

Vine, F. J. and Matthews, D. H.: Magnetic anomalies over oceanic ridges, Nature 199, 947-949, 1963.

Vine, F. J. and Wilson, J.: Magnetic anomalies over a young oceanic ridge off Vancouver Island, Science, 150, 485-489, 1965.

Vogel, K.: Global models of the expanding Earth, in: Frontiers of fundamental physics, edited by: Barone, M. and Selleri, F., Plenum Press, New York, 281-286, 1994.
Völgyesi, L.: Some possible physical reasons of time variation of Earth's gravity field (a possible proof of time change of gravitational constant), Period Politech-Civ, 50, 161-170, 2006.

Wadati, K.: On the activity of deep-focus earthquakes in the Japan islands and neighbourhoods, Geophysical Magazine, 8, 305-325, 1935.

Wallace A. R.: The geographical distribution of animals, 2 Voll, Harper \& Brothers Publishers, New York, 1876.

Wallerstein, G., Iben Jr., I., Parker, P., Boesgaard, A. M., Hale, G. M., Champagne, A. E., Barnes, C. A., Käppeler, F., Smith, V. V., Hoffman, R. D., Timmes, F. X., Sneden, C., Boyd, R. N., Meyer, B. S., and Lambert, D. L.: Synthesis of the elements in stars: forty years of progress, Rev. Mod. Phys., 69, 995-1084, 1997.

Wegener, A.: Die Entstehung der Kontinente und Ozeane, 231 pp., Vieweg \& Sohn Akt.-Ges., Braunschweig, 1929.

White, D. A., Roeder D. H., Nelson T. H., and Crowell, J. C.: Subduction, Geol. Soc. Am., 81, 3431-3432, 1970.

Wilde, S. A., Valley, J. W., Peck, W. H., and Graham, C. M.: Evidence from detrital zircons for the existence of continental crust and oceans on the Earth 4.4 Gyr ago, Nature, 409, 175-178, 2001.

Wilson, T. J.: Geophysics and continental growth, Am. Scientist, 47, 1-24, 1959.

Wilson, T. J.: Some consequences of expansion of the Earth, Nature, 185, 880-882, 1960.

Wilson, T. J.: Continental drift, Sci. Am., 208, 83-100, 1963.

Wilson, T. J.: A new class of faults and their bearing on continental drift, Nature, 207, 343-347, 1965.

Withjack, M. O., Schlische, R. W., and Olsen, P. E.: Development of the passive margin of Eastern North America: Mesozoic rifting, igneous activity, and breakup, in: Regional geology and tectonics: Phanerozoic passive margins, cratonic basins and global tectonic maps, edited by: Roberts, G. and Bally, A. W., Elsevier, New York, 301-335, 2012.

Yabushita, S.: The large-number hypothesis and the Earth's expansion, The Moon and the Planets, 26, 135-141, 1982.

Yada, T., Nakamura, T., Takaoka, N., Noguchi, T., Terada, K., Yano, H., Nakazawa, T., and Kojima, H.: The global accretion rate of extraterrestrial materials in the last glacial period estimated from the abundance of micrometeorites in Antarctic glacier ice, Earth Planets Space, 56, 67-79, 2004.

Zolensky, M., Bland, P., Brown, P., and Halliday, I.: Flux of extraterrestrial materials, in: Meteorites and the early Solar System, edited by: Lauretta, D. S. and McSween, H. Y., University of Arizona Press, 2, 853-869, 2006. 